\title{
O PARCELAMENTO DA DÍVIDA TRIBUTÁRIA COMO FORMA DE EXTINÇÃO DA PUNIBILIDADE
}

\author{
THE INSTALLMENT DEBT TAX AS A MEANS OF EXTINCTION OF PUNISHMENT
}

\section{Resumo}

O presente trabalho dá enfoque ao instituto do parcelamento do crédito tributário como forma de suspensão de sua exigibilidade e extinção da punibilidade na esfera criminal. Trata o tema de medida do Poder Político com o intuito de alcançar êxito em sua política de arrecadação, facilitando o adimplemento dos débitos fiscais, vez que possibilita o seu pagamento parcelado. Para tanto, o Estado vale-se do direito penal como instrumento otimizador da cobrança do crédito tributário. Neste contexto, analisar-se-á o referido instituto tendo como base tanto o princípio da isonomia quanto as leis 9.249/95, 9.964/00, 10.684/03 e a 9.430/96 com alteração dada pela lei 12.382/11, todas reguladoras do parcelamento do débito tributário. Por fim, cabe salientar que os efeitos jurídicos desta espécie de moratória são a suspensão da exigibilidade do crédito tributário; a suspensão da pretensão punitiva, enquanto perdurar o parcelamento do débito; a suspensão do prazo prescricional, na constância do parcelamento; e a extinção da punibilidade, no instante em que o débito é totalmente honrado.

Palavras- chave: Parcelamento. Extinção da punibilidade. Princípio da isonomia.

\begin{abstract}
The present paper focuses on the institute of tax credit installment as a means of suspension of its payment and extinction of criminal liability in the criminal sphere. This paper addresses the issue of measuring the political power in order to succeed in his political fundraising, facilitating the due performance of tax debts, so that enables its deferred payment. Thus, the State relies upon criminal law as an instrument optimizer for charging the tax credit. In this context, this paper will examine the referred institute based on both the principle of equality
\end{abstract}


and the Laws 9.249/95, 9.964/00, 9.430/96 and 10.684/03 with changes by Law 12.382/11, all of which regulates installment of tax debt. Finally, it should be noted that the legal effects of this kind of moratorium is the suspension of the chargeability of the tax credit; the suspension of the punitive claim as long as the installment debt exists; the suspension of the limitations period, in the presence of the installment; and the extinction of criminal liability when the debt is fully honored.

Keywords: Installment. Extinction of criminal liability. Principle of equality.

\section{INTRODUÇÃO}

O Estado de Direito, objetivando proporcionar o bem-estar e a justiça social aos cidadãos, carece da contribuição dos indivíduos por meio do pagamento dos tributos.

Em razão da importância do papel dos tributos na sociedade, o legislador criou normas para proteger os cofres públicos, criminalizando o não pagamento destes em decorrência de fraude e outras condutas tipificadas como nocivas tanto ao erário quanto à sociedade.

Embora não constituam crimes cruéis, como os cometidos contra a integridade física das pessoas, os delitos praticados contra a ordem tributária causam sérios prejuízos ao patrimônio estatal e ao bem-estar de toda a sociedade. Tais prejuízos afligem especialmente as pessoas menos favorecidas financeiramente, que dependem de todo o aparato estatal para viver com um mínimo de dignidade ${ }^{1}$.

Contudo, o sistema penal, acaba por diferenciar sua atuação em relação aos seus diferentes destinatários. De forma geral, são tratadas com maior leniência as condutas próprias de criminosos ricos, enquanto as condutas ilícitas praticadas pelos indivíduos menos favorecidos possuem tratamentos mais rigorosos.

\footnotetext{
${ }^{1}$ De acordo com Nelson Rosenvald (2008, p. 100) a dignidade da pessoa humana é a qualidade intrínseca e distintiva de cada ser humano que o faz merecedor do mesmo respeito e consideração por parte do Estado e da comunidade, implicando, neste sentido, um complexo de direitos e deveres fundamentais que assegurem a pessoa tanto contra todo e qualquer ato de cunho degradante e desumano, como venham a lhe garantir as condições existenciais mínimas para uma vida saudável, além de propiciar e promover a sua participação ativa e co-responsável nos destinos da própria existência e a vida em comunhão com os demais seres humanos.
} 
Nos crimes tributários, ao contrário do que ocorre nos comuns, caso o criminoso pague ou parcele o débito, não poderá ser processado criminalmente devido ao fenômeno da extinção da punibilidade ${ }^{2}$.

Questiona-se assim a validade dessas regras, já que o legislador preferiu claramente dar preferência ao interesse arrecadatório em detrimento dos princípios da ética, isonomia e moralidade administrativa, pois, ao se deparar com a "difícil" escolha entre punir o sonegador e arrecadar, a política criminal do país claramente elegeu a segunda opção.

\section{O PODER DE TRIBUTAR}

Antes de adentrar propriamente ao objeto do presente estudo, cabe primeiramente analisar tanto o poder do ente estatal de exigir o pagamento de tributos aos indivíduos que compõem à sociedade quanto os princípios que regem a relação de tributação, pois, só assim, pode-se ter uma visão um pouco mais contextualizada do instituto a ser analisado.

Indiscutível é o fato de ser o Estado ente soberano. No âmbito internacional representa este a Nação em suas relações com as outras Nações. No âmbito interno, tem o poderio de reger todos os indivíduos que se encontrem em seu território. Configura-se a soberania como a vontade superior às vontades dos indivíduos, como um poder que não reconhece poder superior. (MACHADO, 2011, p. 27).

Em relação à soberania e ao poder de imperium do Estado, Hugo de Brito Machado (2011, p. 27) afirma que "no exercício de sua soberania o Estado exige que os indivíduos lhe forneçam os recursos de que necessita. Institui o tributo. O poder de tributar nada mais é que um aspecto da soberania estatal, ou uma parcela desta".

Nesse sentido, leciona Hugo de Brito Machado o seguinte:

Podemos dizer que a relação tributária decorre, sim, do poder estatal, no sentido de que ela é o veículo de realização do poder de tributar, e embora em cada caso seu nascimento, seu desenvolvimento e sua extinção devam se dar de acordo com a lei, afinal, é o Estado que faz a lei, sendo o poder de tributar uma forma de sua soberania.

Justifica-se o poder de tributar conforme a concepção que se adote do próprio Estado. A idéia mais generalizada parece ser a de que os indivíduos, por seus representantes,

\footnotetext{
${ }^{2}$ A extinção da punibilidade constitui a perda do poder/dever de punir do Estado, podendo ocorrer na fase da
} 
consentem na instituição do tributo, como de resto na elaboração de todas as regras jurídicas que regem a Nação [...]. (MACHADO, 2011, p. 27-28).

Vale dizer que, a relação de tributação não é simples relação de poder, mas relação jurídica, embora o seu fundamento seja a soberania do Estado. Assim, considera-se relação de poder aquela que desponta, desenvolve-se e se desvanece segundo a vontade do soberano e sem observância de qualquer norma que preestabelecida. Já a relação jurídica é aquela que, em contrapartida, nasce, desenvolve-se e se extingue segundo regras já existentes.

\subsection{Poder e competência tributária}

Para melhor compreensão do presente estudo, no âmbito da Teoria do Direito Tributário o termo "poder de tributar" não se confunde com a expressão "competência tributária". A primeira abrange a segunda, e significa a aptidão para realizar a vontade, independentemente do meio eleito. Já a palavra competência alberga a ideia de direito. Assim, geralmente quem tem competência tem também o poder, mas nem sempre assim o é. (MACHADO, 2011, p. 28)

No Estado brasileiro, o poder tributário é repartido entre a União, os Estados-membros, o Distrito Federal e os Municípios. Ao poder tributário juridicamente delimitado, dá-se o nome de competência tributária.

A atribuição de competência é definida pela Constituição Federal devido ao fato de a mesma fazer parte da própria organização jurídica do Estado. Indubitavelmente só às pessoas jurídicas de direito público, dotadas de poder legislativo, pode ser atribuída competência tributária, posto que tal competência apenas pode ser exercida através de lei. (MACHADO, 2011, p. 28).

Nesse sentido, Hugo de Brito Machado assevera:

Em princípio a competência tributária compreende a competência legislativa e a capacidade tributária. No que concerne à competência tributária, é indelegável. Pode, todavia, ser delegada por uma pessoa jurídica de direito público a outra, no que concerne à capacidade tributária ou capacidade para ser sujeito ativo da obrigação tributária, que

pretensão punitiva ou executória. 
compreende as funções de arrecadar ou fiscalizar tributos ou de executar leis, serviços, atos ou decisões administrativas em matéria tributária. (MACHADO, 2011, p. 29).

Dessa forma, a capacidade tributária não se confunde com a competência. Esta é atribuída pela Constituição a um ente estatal dotado de poder legislativo, sendo exercida mediante edição de lei. Já a capacidade é atribuída pela Constituição ou por uma lei, a ente estatal não necessariamente dotado de poder legislativo, sendo exercida mediante atos administrativos.

\section{OS PRINCÍPIOS JURÍDICOS DA TRIBUTAÇÃO}

Partindo-se da ideia de que a relação de tributação não é simples relação de poder, mas sim relação jurídica, e tendo em vista que os princípios constituem proposições genéricas que servem de substrato para a organização de um ordenamento jurídico, necessário se torna a abordagem dos princípios jurídicos da tributação.

Dentre os vários princípios, devem ser enfatizados aqueles que, em razão de seu caráter geral, podem ser considerados comuns a todos os sistemas jurídicos, ou, pelo menos, aos mais importantes.

\subsection{Legalidade}

Tem-se pelo princípio da legalidade tributária a garantia de ser vedado exigir ou aumentar tributo sem que a lei o estabeleça. (CF, art. 150, 1).

Sobre o princípio da legalidade, assevera Luciano Amaro que:

[...] O princípio é informado pelos ideais de justiça e de segurança jurídica, valores que poderiam ser solapados se à administração pública fosse permitido, livremente, decidir quando, como e de quem cobrar tributos.

Esse princípio é multissecular, tendo sido consagrado, na Inglaterra, na Carta Magna de 1215, do Rei João Sem Terra, a quem os barões ingleses impuseram a necessidade de obtenção prévia de aprovação dos súditos para a cobrança de tributos (no taxation without representation). (AMARO, 2005, p.111). 
Vale mencionar ainda que, de acordo com Amaro (2005, p. 112), o teor do princípio da legalidade vai muito além da simples permissão do legislativo para que o Estado cobre tal ou qual tributo. É imperioso que a lei defina in abstracto todos os aspectos essenciais para que, in concreto, se possa determinar quem deverá pagar, quanto deverá ser pago, a quem pagar, e à vista de que fatos ou circunstâncias. Dessa maneira, a lei deve prever não apenas a hipótese de incidência em todos os seus aspectos, mas tudo quanto seja necessário à existência da relação obrigacional tributária.

\subsection{Anterioridade}

Nas palavras do art. 150, 111, “b”, da Constituição Federal - CF/88 é proibido à exigência de tributos "no mesmo exercício financeiro em que haja sido publicada a lei que os instituiu ou aumentou". Tal dispositivo institui o princípio da anterioridade.

Em dezembro de 2003 foi acrescido no referido artigo, por meio da Emenda Constitucional n. 42, a alínea "c", para vedar, ainda, que o tributo seja cobrado antes de decorridos noventa dias da data de publicação da lei que o instituiu ou aumentou (anterioridade “nonagesimal”). (AMARO, 2005, p. 120-121).

Seguindo a presente linha de raciocínio, elucida Hugo de Brito Machado que:

para que o tributo seja cobrado a partir de $1^{\circ}$ de janeiro já não basta que a lei seja publicada até o último dia do exercício anterior, ou seja, já não basta a obediência ao princípio da anterioridade. Para que o tributo seja devido a partir de $1^{\circ}$ de janeiro, a lei que o criou ou aumentou deve ser publicada pelo menos 90 dias antes. Entretanto, a exigência da anterioridade não se confunde com a exigência da vacância legal de 90 dias. Assim, se a lei que cria ou aumenta o tributo é publicada até o último dia de dezembro está atendida a exigência do princípio da anterioridade, e a exigência da vacância de 90 dias faz com que a vigência da lei só tenha início 90 dias depois de sua publicação. (MACHADO, 2011, p. 35).

Merece destaque a abordagem feita por Hugo de Brito Machado (2011, p. 36) no sentido de que o princípio da anterioridade da lei tributária não se confunde com o princípio da irretroatividade da lei, que é princípio geral de Direito e vigora, portanto, também no direito tributário. Na Teoria Geral, a irretroatividade quer dizer que a lei deve ser anterior ao fato que 
qualifica juridicamente. Já no direito tributário, quer dizer que a lei deve ser anterior ao fato gerador do tributo por ela criado ou majorado (CF, art. 150, 111, "a").

Assim, conclui-se que anterioridade, princípio constitucional tributário, é irretroatividade qualificada, exigindo para tanto a edição de lei anterior ao início do exercício financeiro no qual o tributo é cobrado (CF, art. 150, 111, "b").

\subsection{Igualdade}

O princípio da igualdade é o reflexo na área tributária do princípio geral da isonomia jurídica, ou princípio pelo qual todos são iguais perante a lei. Apresenta-se o presente princípio ao proibir a criação de "tratamento dessemelhante entre contribuintes que se encontrem em situação homóloga, proibida qualquer distinção em função de ocupação profissional ou ofício por eles exercido, independentemente da denominação jurídica dos rendimentos, tributos ou direitos." (AMARO, 2005, p. 135).

Os embaraços no que tange ao princípio da isonomia surgem quando se trata sobre a questão de saber se o legislador pode instituir hipóteses discriminatórias, e qual o critério de discrime que pode validamente utilizar. Na realidade a lei sempre discrimina. Seu papel crucial consiste exatamente na disciplina das desigualdades naturais que existem entre as pessoas. Dessa forma, o importante, portanto é saber como será válida a discriminação. Quais os critérios admissíveis, e quais os critérios que implicam lesão ao princípio da isonomia. (MACHADO, 2011).

\subsection{Capacidade Contributiva}

A Carta Política de 1988 estabelece no art. 145, $\S 1^{\circ}$, que, "sempre que possível, os impostos terão caráter pessoal e serão graduados segundo a capacidade econômica do contribuinte, facultado à Administração Tributária, especialmente para conferir efetividade a esses objetivos, identificar, respeitados os direitos individuais e nos termos da lei, o patrimônio, os rendimentos e as atividades econômicas do contribuinte". 
De acordo com Luciano Amaro (2005, p. 142), o princípio da capacidade contributiva diz respeito aos tributos em geral, e não somente aos impostos, embora apenas em relação a estes esteja expressamente positivado na $\mathrm{CF} / 88$, já que outras espécies tributárias podem levar em consideração à capacidade contributiva, em especial as taxas, cabendo evocar que, em várias situações, o próprio texto constitucional veda a cobrança de taxas em hipóteses nas quais não se vislumbra a capacidade econômica (cf., por exemplo, art. $5^{\circ}$, LXXVII, CF/88).

Complementa Machado (2011, p. 39) que não é razoável entender-se que o legislador tem ampla liberdade para resolver quando é e quando não é possível exigir-se obediência ao princípio em tela, porque tal compreensão anula inteiramente a sua supremacia.

\subsection{Vedação ao Confisco}

A CF/88 estabelece que seja proibido à União, aos Estados, ao Distrito Federal e aos Municípios utilizar tributo com efeito de confisco. Nestes termos, o preceito constitucional pode ser invocado sempre que o contribuinte entender que o tributo, no caso, lhe está sequestrando bens. (MACHADO, 2011, p. 40- 41).

Merece destaque que a vedação ao confisco é atinente ao tributo e não à penalidade pecuniária, vale dizer, à multa, pois tributo e multa são essencialmente distintos. O ilícito é pressuposto essencial desta, e não daquele. (MACHADO, 2011, p. 41).

Sobre a distinção entre multa e tributo, assevera Hugo de Brito Machado que:

No plano estritamente jurídico, ou plano da ciência do Direito, em sentido estrito, a multa distingue-se do tributo porque em sua hipótese de incidência a ilicitude é essencial, enquanto a hipótese de incidência do tributo é sempre algo lícito. [...] No plano teleológico a distinção é também evidente. $\mathrm{O}$ tributo tem por finalidade o suprimento dos recursos financeiros de que o Estado necessita, e por isto mesmo constitui uma receita ordinária. Já a multa não tem por finalidade a produção de receita pública, e sim desestimular o comportamento que configura sua hipótese de incidência, e por isto mesmo constitui uma receita extraordinária ou eventual. (MACHADO, 2011, p. 41).

Dessa maneira, por constituir um encargo aos cidadãos, o tributo deve ser suportável, na medida em que não deverá impossibilitar o contribuinte de usufruir normalmente dos bens da 
vida. Já a multa, por ter finalidade desestimulante, necessariamente deverá representar uma cobrança significativa, sendo sempre confiscatória.

\section{O PARCELAMENTO DO CRÉDITO TRIBUTÁRIO COMO CAUSA EXTINTIVA DA PUNIBILIDADE NOS CRIMES TRIBUTÁRIOS}

Inicialmente, cabe esclarecer que a punibilidade, segundo Andreas Eisele (2002, p. 106), "é a concreta possibilidade jurídica (poder) de o Estado aplicar (ou executar) uma sanção, em face do sujeito ativo de um crime." Dessa forma, pode-se dizer que a punibilidade, também chamada de ius puniendi, é a capacidade do Estado de fazer valer o seu direito de punir em determinado espaço de tempo algum infrator.

Essa possibilidade, todavia, é limitada, tendo em vista que em algumas situações o Estado tem o exercício do ius puniendi excluído, por opção de política criminal, questão em que não poderá aplicar ou executar a pena correspondente ao crime.

Tais situações resumem-se nas causas extintivas da punibilidade, cuja ocorrência elimina a possibilidade jurídica de aplicação de uma pena ao autor de um delito, não obstante o fato praticado continue sendo criminoso.

Nos crimes contra a ordem tributária, a previsão de efeitos jurídicos excepcionais à reparação do dano é um instituto tradicional no âmbito do Direito Penal Tributário brasileiro. (EISELE, 2002, p. 108).

Este distinto tratamento baseia-se na expansão, tanto na consequência da reparação do dano, quanto nas possibilidades de incidência destes efeitos.

No que tange aos efeitos da reparação do dano, diferentemente do que ocorrem em relação aos demais crimes, cujo resultado jurídico é a incidência de uma causa de atenuante ou de diminuição de pena, nos crimes contra a ordem tributária essa hipótese poderá acarretar a extinção da punibilidade do agente. (EISELE, 2002, p. 106).

À semelhança, quando o caso for de reparação do dano mediante pagamento parcelado, a legislação penal tributária prevê a suspensão da pretensão punitiva até o pagamento integral, caso em que o sujeito terá extinta a sua punibilidade. 
Sobre as hipóteses de efeitos jurídicos excepcionais, afirma Andreas Eisele (2002, p. 107) que o Direito Penal assume um caráter funcional, no sentido de ser utilizado como instrumento de otimização das atividades da Administração.

Nesse sentido, ainda afirma que:

\begin{abstract}
Essa utilização do Direito Penal como instrumento otimizador da cobrança do crédito tributário, além de ser questionável no âmbito da legitimidade de sua instituição, acarreta dois efeitos prejudiciais ao sistema.

O primeiro deles consiste na afetação da eficácia da finalidade protetora de bens jurídicos conferidos à norma penal, pois a perspectiva da possibilidade de posterior elisão dos efeitos penais do fato pela reparação do dano diminui o efeito intimidatório esperado da norma penal. (EISELE, 2002, p. 107-108).
\end{abstract}

Como consequência desta funcionalização, o sistema penal, tanto abstratamente como concretamente, acaba por diferenciar sua atuação em relação aos seus diferentes destinatários. De acordo com Marcelo Cunha de Araújo (2010, p. 71), de maneira geral, são tratadas com maior condescendência as condutas próprias dos potenciais criminosos ricos, enquanto os sujeitos à margem da sociedade são regidos com maior rigor.

Nesse sentido, destaca o referido autor:

\begin{abstract}
Cabe registrar aqui a visível faceta da diferenciação calcada nos distintos ofensores ao patrimônio alheio. Nos delitos tributários, ao contrário do que ocorre nos outros crimes contra o patrimônio, caso o criminoso salde a dívida fiscal (ou mesmo a parcele, em acordo com o Estado, visando ao seu futuro pagamento), não poderá a ação penal seguir seu trâmite regular. Aquele que furta coisa alheia móvel, a seu turno, ainda que devolva espontaneamente, ou seja, recuperada imediatamente a res furtiva (coisa furtada), pouco ou nenhum benefício criminal receberá. Tal distinção, com toda certeza, não ocorre por acaso. (ARAÚJO, 2010, p. 71).
\end{abstract}

É relevante perceber que tanto os crimes hediondos, como os equiparados (lei n ${ }^{\circ}$ 8072/90) são, em tese, crimes cometidos, via de regra, pelas classes menos favorecidas, como o latrocínio; extorsão qualificada pela morte; extorsão mediante seqüestro; estupro; tráfico; homicídio qualificado, entre outros. É no mínimo de se estranhar o fato de que, em um país pobre e de 
notoriamente com altos níveis de corrupção, como o Brasil, não são considerados hediondos os crimes contra a administração pública, os tributários e os financeiros. (ARAÚJO, 2010, p. 72).

Dessa forma, deve-se ter em mente que a funcionalização do Direito Penal no campo tributário, mais do que depreciar este instituto tão essencial à vida em sociedade, acaba por criar uma regra excepcional para uma espécie delitiva, afetando sensivelmente o princípio da igualdade.

\subsection{Principais legislações relativas à extinção da punibilidade pelo pagamento/parcelamento do crédito tributário.}

De fato, quatro leis principais tratam da questão relativa à extinção da punibilidade pelo pagamento do tributo.

A primeira, lei n. 9.249 de 26 de dezembro de 1995, em seu art. 34, prevê que extingue-se a punibilidade dos crimes definidos na lei $\mathrm{n}^{\circ}$ 8.137, de 27 de dezembro de 1990, e na lei n. 4.729, de 14 de julho de 1965, quando o agente promover o pagamento do tributo ou contribuição social, inclusive acessórios, antes do recebimento da denúncia.

Pela leitura de seu art. 34 verifica-se que a lei ${ }^{\circ}$ 9.249/95 não distingue se o pagamento do tributo ou contribuição deverá ser a vista ou não, apenas utiliza-se da expressão "promover o pagamento", que, literalmente, significa dar início ao procedimento de quitação, o qual também ocorre com o parcelamento.

A segunda, lei n. 9.964, de 10 de abril de 2000, que instituiu o Programa de Recuperação Fiscal - Refis, praticamente repetiu a causa extintiva da punibilidade prevista no art. 34 da lei $\mathrm{n}^{\circ}$ 9.249/95 em seu art. $15, \S 3^{\circ}$. Contudo, a inovação da presente lei trata da possibilidade do parcelamento do débito tributário, o qual ocasiona a suspensão do processo e da prescrição penal desde que a inclusão no referido Programa tenha ocorrido antes do recebimento da denúncia criminal, conforme se infere do "caput" do art. 15 da referida lei.

A terceira, lei n. 10.684, de 30 de maio de 2003, conhecida como Lei do PAES, que dispõe sobre parcelamento de débitos junto à Secretaria da Receita Federal, à Procuradoria-Geral da Fazenda Nacional e ao Instituto Nacional do Seguro Social, passou a conferir regras próprias no tocante aos efeitos penais e processuais penais do pagamento e do parcelamento de débitos tributários. 
Prevê o referido diploma legal que, a prescrição criminal não corre durante o período de suspensão da pretensão punitiva (período de parcelamento) para as pessoas jurídicas (art. $8^{\circ}, \S 1^{\circ}$ A), e que se extingue a punibilidade dos crimes referidos neste artigo quando a pessoa jurídica relacionada com o agente efetuar o pagamento integral dos débitos oriundos de tributos e contribuições sociais, inclusive acessórios (art. $9^{\circ}, \S 2^{\circ}$ ).

Da leitura da lei n. 10.684 infere-se que é admitido o pagamento do tributo a qualquer tempo, independentemente de ter sido efetuado antes ou após o recebimento da denúncia, podendo concluir que, não havendo limite temporal para o pagamento integral, à vista ou parcelada, ou até mesmo realizada em grau recursal, será extinta a punibilidade do agente.

Merece destaque que, ao contrário do REFIS, a presente lei em seu art. $2^{\circ}$, parágrafo único, restringiu os efeitos do pagamento aos tributos pertencentes à União apenas e, também, restringiu os efeitos apenas às pessoas jurídicas, conforme art. $8^{\circ}, \S 2^{\circ}$.

Por outro lado, o PAES, diferentemente do que ocorre com o REFIS (art. $1^{\circ}$ ), admite o parcelamento de débitos de pessoas físicas (art. $1^{\circ}, \S 3^{\circ}$, III), porém o dispositivo que trata da extinção da punibilidade (art. $9^{\circ}, \S 2^{\circ}$ ) fez referência, somente, às pessoas jurídicas.

Menciona-se que, invocando o referido princípio da isonomia, pode-se questionar a validade das restrições acima, pois, devido à natureza do instituto (moratória), os efeitos decorrentes devem incidir sobre todas as situações análogas, independente do tributo ou do nome do programa que instituiu o benefício.

Enfim, no âmbito penal, a lei n. 9.430, de 27 de dezembro de 1996, que dispõe sobre a legislação tributária federal, as contribuições para a seguridade social e o processo administrativo, dispõe em seu art. 83, primeiro artigo do título "Crime contra a Ordem Tributária" que:

A representação fiscal para fins penais relativas aos crimes contra a ordem tributária previstos nos arts. $1^{\circ}$ e $2^{\circ}$ da Lei no 8.137, de 27 de dezembro de 1990 , e aos crimes contra a Previdência Social, previstos nos arts. 168-A e 337-A do Decreto-Lei no 2.848, de 7 de dezembro de 1940 (Código Penal), será encaminhada ao Ministério Público depois de proferida a decisão final, na esfera administrativa, sobre a exigência fiscal do crédito tributário correspondente.

No tocante ao parcelamento, dispõe seus parágrafos: 
$\S 1^{\circ} \mathrm{Na}$ hipótese de concessão de parcelamento do crédito tributário, a representação fiscal para fins penais somente será encaminhada ao Ministério Público após a exclusão da pessoa física ou jurídica do parcelamento.

$\S 2^{\circ}$ É suspensa a pretensão punitiva do Estado referente aos crimes previstos no caput, durante o período em que a pessoa física ou a pessoa jurídica relacionada com o agente dos aludidos crimes estiver incluída no parcelamento, desde que o pedido de parcelamento tenha sido formalizado antes do recebimento da denúncia criminal.

$\S 3^{\circ}$ A prescrição criminal não corre durante o período de suspensão da pretensão punitiva.

$\S 4^{\circ}$ Extingue-se a punibilidade dos crimes referidos no caput quando a pessoa física ou a pessoa jurídica relacionada com o agente efetuar o pagamento integral dos débitos oriundos de tributos, inclusive acessórios, que tiverem sido objeto de concessão de parcelamento.

Importante ressaltar que os aludidos parágrafos do art. 83 da lei 9.430/66 foram todos incluídos pela lei n. 12.382, de 25 de fevereiro de 2011, e a alteração primordial no âmbito criminal encontra-se na última parte do parágrafo segundo do presente artigo, dispondo que o pedido de parcelamento deverá ser formalizado necessariamente antes do recebimento da denúncia criminal.

Vale recordar que o art. $2^{\circ}, \S 1^{\circ}$, da Lei de Introdução às Normas do Direito Brasileiro dispõe que "a lei posterior revoga a anterior quando expressamente o declare, quando seja com ela incompatível ou quando regule inteiramente a matéria de que tratava a lei anterior”.

Dessa forma, levando-se em consideração que a lei n. 12.382/11 trata-se tanto de uma lei posterior, quanto de uma lei mais grave, aos delitos tributários praticados antes de sua vigência (28 de fevereiro de 2011), por força do art. $5^{\circ}, \mathrm{XL}$, da $\mathrm{CF} / 88$ que dispõe que a lei penal não retroagirá, salvo para beneficiar o réu, deverá ser aplicado o disposto no art. $9^{\circ}$, caput e $\S 1^{\circ}$, da lei n. 10.684, que não delimita tal marco temporal. Já em relação aos crimes praticados após sua entrada em vigor, serão eles regidos de acordo com os seus ditames.

Para concluir, dispõe Luiz Flávio Gomes (2002, p. 24) que a regra atual no direito brasileiro, portanto é a que se extingue o jus puniendi, nos crimes tributários, quando o agente promove o pagamento do tributo antes do recebimento da denúncia.

E, seguindo toda a linha de raciocínio, conclui: 
O limite temporal máximo, de qualquer modo, é o do recebimento da denúncia. Recebimento não se confunde com oferecimento. Importa, destarte, a data em que o juiz recebe não a data em que houve o oferecimento da denúncia. Já se decidiu que o limite temporal (pagamento antes do recebimento da denúncia) seria inconstitucional, por violar o princípio da retroatividade da lei penal mais benéfica $\left(\mathrm{CF}\right.$, art. $5^{\circ}, \mathrm{XL}$ e art. $2^{\circ}$ do CP) (TRF $1^{\circ}$ R., Ac. 1996.01.03936-8/DF, Cândido Ribeiro). (GOMES, 2002, p. 24)

Neste sentido, pode-se afirmar que, atualmente, e com todo o respaldo do ordenamento jurídico pátrio, extinguirá a punibilidade do agente infrator o pagamento da totalidade do crédito tributário antes do recebimento da denúncia pelo juiz da causa.

\subsection{Efeitos do parcelamento}

Segundo Andreas Eisele (2002, p. 118) o abalizamento dos efeitos jurídico-penais da moratória, principalmente na forma de parcelamento do débito tributário, tem sido motivo de grande discussão no Brasil, fundamentalmente em face da polêmica que trata da definição de se essa hipótese deveria ou não ser equivalente ao pagamento, de modo a ocasionar a extinção da punibilidade do agente em face do delito.

Para o autor, neste ambiente, tanto a lei que instituiu o REFIS, lei n. 9.964/00, quanto a lei n. 10.684, que trata do PAES, podem ter solucionado tal controvérsia ao instituir uma solução intermediária.

As mencionadas leis não nivelaram a moratória ao pagamento, porém estabeleceram uma alternativa que impede a súbita aplicação das consequências jurídico-penais do fato durante o interstício em que o sujeito estiver incluído na condição de beneficiário da moratória. (EISELE, 2002, p. 118).

Para Eisele (2002, p. 118), sem dúvida, o parcelamento proveniente da moratória apenas suspende o crédito tributário, não o extinguindo, motivo pelo qual não equivale ao pagamento para caracterizar a hipótese de extinção da punibilidade, prevista no art. 34 da lei n. 9.249/95, por arrependimento posterior.

Seguindo esta linha de raciocínio, Eisele leciona que: 
Tal conclusão decorre não apenas do fato de que a moratória não configura novação (figura, aliás, inexistente no Direito Tributário, eis que a obrigação tributária tem natureza originária ex lege e não contratual), mas, igualmente, do sentido teleológico da norma que visa à reparação do dano, a qual pode não ocorrer se o agente, após a concessão de moratória, obtém o pronunciamento judicial declaratório de extinção da punibilidade e deixa de pagar as parcelas da dívida a partir de então vincendas. (EISELLE, 2002, p. 118).

Dessa maneira, tendo em vista o Poder Político alcançar êxito em sua política arrecadatória, além de facilitar o pagamento parcelado dos débitos e impor algumas condições, previu no parcelamento a figura da suspensão da pretensão punitiva.

Como efeito penal da suspensão da punibilidade, há a figura da suspensão do prazo prescricional. Segundo Luiz Flávio Gomes (2002, p. 54), o Estado, uma vez suspensa a pretensão punitiva, não pode agir, nem sequer investigar por inquérito ou instrutoriamente, salvo caso de prova urgente, mas também não correrá a prescrição, nada mais junto e proporcional.

Para elucidar, vale dizer que, se a prescrição tem como fundamento a inércia do Estado, quando ele não pode agir, não há que se falar em prescrição (GOMES, 2002, p. 54).

Dessa forma, conclui-se que o parcelamento, uma vez firmado, suspende a exigibilidade do crédito, honrado, extingue-o, assim como a punibilidade do infrator.

\section{CONSIDERAÇÕES FINAIS}

Em síntese, pode ser dito que, para os crimes que tenham os tributos em geral por objeto material, a reparação completa do dano anteriormente ao recebimento da denúncia criminal extingue a punibilidade do sujeito, referente ao fato.

O parcelamento da dívida tributária anterior ao recebimento da denúncia criminal suspende a exigência e a punibilidade do sujeito. Honrado o compromisso, extingue-se a pretensão punitiva estatal.

A reparação parcial do dano ocorrida antes do recebimento da denúncia, ou a reparação completa realizada posteriormente ao início do processo penal, acarreta a incidência de uma circunstância atenuante de pena. 
Não é por acaso, como já mencionado, que Andreas Eisele afirma que a utilização do Direito Penal como mecanismo otimizador da cobrança do crédito tributário acarreta efeitos prejudiciais ao sistema, um deles, é a redução do efeito intimidatório esperado da norma penal.

Nesse panorama, incontestável é que os delitos praticados contra a ordem tributária causam danos gravíssimos ao patrimônio estatal e ao bem-estar da coletividade, fato que põe em risco a própria coesão social. Tais danos afligem toda a sociedade, especialmente as pessoas menos favorecidas financeiramente, que dependem de um eficaz sistema de socorro social para viver com um mínimo de dignidade.

Porém, como visto, o sistema penal, tanto abstratamente como concretamente, acaba por diferenciar sua atuação em relação aos seus diferentes destinatários. Os maiores exemplos dessa distinção são os delitos patrimoniais, como o furto, que mais do que prever punição desproporcional a certos casos de subtração de objetos de pequeno valor, caso o delinquente restitua o objeto subtraído, não terá sua punibilidade extinta, mas apenas reduzida a sua pena.

Assim, pode-se concluir dizendo que questionável são, quanto à sua validade, ou até mesmo constitucionalidade, as regras que dispõem sobre o pagamento/parcelamento da dívida tributária como forma de suspensão e, consequentemente, extinção da punibilidade.

Em um primeiro momento, questiona-se pelo fato de o legislador ter optado claramente por dar preferência ao interesse arrecadatório em detrimento dos princípios da ética, isonomia e Moralidade Administrativa, pois, ao se deparar com a "difícil" escolha entre punir o sonegador e arrecadar, a política criminal do país claramente se simpatizou com a segunda opção.

E, em um segundo momento, questiona-se por ter criado uma regra excepcional para uma espécie delitiva (pagamento/parcelamento como forma de extinção da punibilidade), afetando claramente novamente o princípio da igualdade (isonomia).

\section{REFERÊNCIAS}

AMARO, Luciano. Direito Tributário Brasileiro. 11. ed. São Paulo: Saraiva, 2005.

\section{ARAÚJO, Marcelo Cunha. Só é preso quem quer!: impunidade e ineficiência do sistema}

criminal brasileiro. 2. Ed. rev. e atual. Rio de Janeiro: Brasport, 2010. 
EISELE, Andreas. Crimes contra a ordem tributária. 2. ed. São Paulo: Dialética, 2002.

FARIAS, Cristiano Chaves; ROSENVALD, Nelson. Direito Civil - Teoria Geral. 7. ed. Rio de Janeiro: Editora Lumen Juris, 2008.

GOMES, Luiz Flávio. Crimes Contra a Ordem Tributária. São Paulo: IOB, 2002. Outros autores: Luiz Flávio Gomes; Misabel Abreu Machado Derzi; Wagner Balera.

MACHADO. Hugo de Brito. Curso de Direito Tributário. 32. ed. São Paulo: Malheiros, 2011. 